\title{
Potencial uso en la evaluación de lanas y fibras de animales de un novedoso caracterizador electrónico
}

\author{
Potential use in the eVAluation OF WOOL AND ANIMAL FibRes OF A NOVEL \\ ELECTRONIC CHARACTERIZER
}

Edgar Carlos Quispe Peña ${ }^{1,4}$, Diego Sacchero ${ }^{2}$, Max David Quispe Bonilla ${ }^{3}$

\section{Resumen}

Se desarrolló y validó un novedoso Caracterizador Electrónico de Fibras (CEF). En el desarrollo del CEF se utilizaron y ensamblaron componentes mecánicos, ópticos, electrónicos e informáticos. Para la calibración, validación y evaluación del potencial uso en fibras de animales se tomaron muestras de patrones de diámetros conocidos de tops de ovinos, mohair, alpacas, así como muestras de fragmentos de fibras de vicuñas y de alpacas, que fueron medidas antes y después de calibrar con el CEF, OFDA2000 en modo 100 y Laserscan. También se midieron 299 fragmentos de muestras de alpacas sin lavar en el OFDA 2000 y en el CEF bajo condiciones de campo. El CEF desarrollado permite procesar las imágenes de fibras obtenidas mediante tecnología de visión artificial, realizando más de 8000 mediciones por muestra en 30 segundos. Los resultados se muestran en una interfaz gráfica amigable que forma parte del software propietario elaborado para el CEF. La calibración para la conversión de pixeles a micras se ajustó a regresiones lineales con coeficientes de correlación muy cercanos a 1. Los resultados de la validación indican que el CEF tiene alta precisión y exactitud para la media de diámetro de fibra (MDF) con rangos de tolerancia ubicados dentro de los exigidos por IWTO y ASTM, para el caso de lana de ovino y fibra de mohair, aunque un poco bajos para el caso de fibras de vicuñas. De otro lado, se encontró una correlación cercana a 1 para mediciones obtenidas por el OFDA 2000 y el CEF respecto a fibras de alpacas para MDF y factor de confort, tanto en el caso de uso en laboratorio como en campo. Finalmente, en la evaluación de fibras de cachemira se encontró que los resultados son característicos de este tipo de fibras. Se concluye que el CEF puede utilizarse en la evaluación de lanas de ovinos y fibras de mohair y alpacas con gran precisión y exactitud, debiéndose realizar más evaluaciones para fibras de vicuñas y cachemira.

Palabras clave: equipo automático; precisión; fibra animal; calidad de fibra; diámetro promedio de fibra

${ }^{1}$ Universidad Nacional Autónoma de Chota, Cajamarca, Perú

${ }^{2}$ Laboratorio de Fibras Textiles, Instituto Nacional de Tecnología Agropecuaria (INTA), Bariloche, Argentina

${ }^{3}$ Maxcorp Technologies S.A.C., Santa Anita, Lima, Perú

${ }^{4}$ E-mail: edgarquispe62@gmail.com

Recibido: 15 de octubre de 2017

Aceptado para publicación: 14 de febrero de 2018 
A novel Fibre Electronic Characterizer (called Fiber EC) was developed and validated. In the development of the Fiber EC, mechanical, optical, electronic and computer components were used and assembled. For the calibration, validation and evaluation of the potential use in animal fibres samples of well-known diameter patterns were taken from tops of sheep, mohair, alpacas, as well as samples of fibre snippets of vicuñas and alpacas, which were measured before and after calibration with the Fiber EC, OFDA2000 in 100 mode and Laserscan. Snippets $(n=299)$ of unwashed alpaca samples were also measured in the OFDA 2000 and in the Fiber EF under field conditions. The developed Fiber EC allows to process the images of fibres obtained by artificial vision technology, making more than 8000 measurements per sample in 30 seconds. The results are shown in a friendly graphical interface that is part of the proprietary software developed for the Fiber EC. The calibration for the conversion of pixels to microns was adjusted to linear regressions with correlation coefficients very close to 1 . The results of the validation indicate that the Fiber EF has high precision and accuracy for the average fibre diameter (AFD) with ranges of tolerance within those required by IWTO and ASTM, in the case of sheep wool and mohair fibres, although a little low in the case of vicuña fibres. On the other hand, a correlation close to 1 was found for measurements obtained by OFDA 2000 and the Fiber EC with respect to alpaca fibres for MDF and comfort factor, both in the case of laboratory and field use. Finally, in the evaluation of cashmere fibres it was found that the results are characteristic of this type of fibres. It is concluded that the Fiber EC can be used in the evaluation of sheep wool and mohair and alpaca fibres with great precision and accuracy, and should carry out more evaluations for vicuña and cashmere fibres.

Key words: automatic equipment; precision; animal fibre; fibre quality; average fibre diameter

\section{INTRODUCCIÓN}

A nivel de Sudamérica se estima una producción de 143700 t de lana y más de 5000 t de fibras de cabras y camélidos (Cardellino y Mueller, 2008). La calidad es el principal elemento multifactorial que afecta la ruta y la eficiencia del procesamiento, el uso potencial de los productos finales, así como el precio de la fibra como materia prima o como producto textil (Cottle y Baxter, 2015).

Los equipos utilizados en la actualidad permiten cuantificar objetivamente la calidad de las lanas y fibras (Cottle y Baxter, 2015); sin embargo, estos equipos requieren pasar por un proceso de calibración y validación (Hazelton, 2009). La calibración es el conjunto de operaciones que relacionan los valo- res indicados por un instrumento de medida con los valores correspondientes conocidos de un mensurando (UNIDO, 2006,) llamados también patrones, pudiéndose obtener indicadores de precisión, exactitud, repetibilidad, reproducibilidad y resolución respecto al equipo en cuestión (U.S. Department of Health and Human Services, 2011).

El OFDA (equipo basado en el análisis de imágenes) está calibrado según la norma IWTO-47 (IWTO-47, 2007) y el Laserscan (basado en la técnica de fotometría) según IWTO-12, (IWTO-12, 2003), para lo cual utilizan ocho muestras patrones de top de lana de ovinos. Los valores de tolerancia para ambos equipos son de $0.3,0.6,0.8,1.0,1.2 \mathrm{y}$ 1.4 para rangos de diámetro de fibra menor a 15.0 , entre 15.1 y $20.0,20.1$ y $25.0,25.1$ y 
$30.0,30.1$ y 35.0 y mayores a $35.1 \mu \mathrm{m}$, respectivamente. La precisión para el caso del microscopio de proyección, según IWTO-8 (IWTO-8, 2004), se considera dentro de los límites de 0.9 y 1.1 para fibras con diámetros medios de 22 y $35 \mu \mathrm{m}$; en tanto que para el Airflow, según IWTO-28 (IWTO-28, 2000), los valores de rangos críticos son de $0.4,0.6$, $0.8,0.9,1.1$ y $1.2 \mu \mathrm{m}$ para los mismos rangos de diámetros de fibra considerados para el OFDA y Laserscan.

Las tolerancias para los equipos se incrementan de acuerdo al incremento del rango del diámetro de fibras a medir, lo cual se debe a la existencia de una relación directa entre el diámetro con la variación y el número de fibras a medir; de modo que para obtener un límite de confianza de $\pm 0.2 \mu \mathrm{m}$ en fibras de 18 y $37 \mu \mathrm{m}$ de diámetro se requieren entre 1540 y 9700 mediciones, mientras que para una tolerancia de \pm 0.5 se requieren medir entre 250 y 1500 fibras (ASTM, 2001). Es por esto por lo que en equipos como el OFDA y el Laserscan se miden más de 2000 fibras.

Bajos intervalos de confianza definen la buena precisión de un equipo. Al evaluarse la precisión del OFDA2000, Laserscan y el Fleecescan se encontraron valores de intervalos de confianza al $95 \%$ entre $1.02 \mathrm{y}$ $1.41 \mu \mathrm{m}, 0.6$ y $0.8 \mu \mathrm{m}$ y 2.2 y $3.5 \%$ para el diámetro de fibra, desviación estándar y coeficiente de variación, respectivamente (Marler et al., 2002). Similares valores fueron encontrados cuando se evaluó la precisión y exactitud de siete procedimientos de medición utilizando diversos equipos, concluyendo que el muestreo del costillar medio y el procedimiento en laboratorio tienen mejores y equivalentes intervalos de confianza, siendo \pm 1.04 y $1.05 \mu \mathrm{m}$ para el Laserscan y el OFDA100 (Marler y Baxter, 2004). Se disponen de estudios donde han sido comparados equipos como el Laserscan, OFDA y el Airflow (Baxter, 1998; Baxter y Marler, 2004; Heath et al., 2006).
Por otro lado, se puede observar que se disponen de pocos equipos que se pueden utilizar para la evaluación de fibras y lanas, y cuyo desarrollo se deben principalmente a la industria australiana (OFDA y Laserscan); sin embargo, sus precios son onerosos y, por tanto, de difícil acceso a los productores, de allí que se requiera desarrollar otros equipos que sean capaces de caracterizar diversos tipos de lanas y fibras. El presente trabajo tuvo como objetivo desarrollar un nuevo equipo para la evaluación de fibras y lanas, así como realizar la calibración y validación del mismo utilizando diversos tipos de fibras de origen animal.

\section{Materiales y Métodos}

\section{Localización y Duración}

El diseño, desarrollo y construcción del Caracterizador Electrónico de Fibras (CEF) se llevó a cabo en el Laboratorio de Electrónica y Mecánica de MAXCORP Technologies S.A.C., ubicado en Lima, Perú. El proceso de calibración y validación se llevó a cabo en el Laboratorio de Fibras Textiles del Instituto Nacional de Tecnología Agropecuaria (INTA), en Bariloche, Argentina. Asimismo, las mediciones en mechas de fibras de alpacas a condiciones de campo se llevaron a cabo en la Ciudad Universitaria de Paturpampa, Universidad Nacional de Huancavelica (UNH), Perú.

El trabajo se inició en marzo de 2015, empezando con el diseño del CEF y culminándose en octubre de 2016 con la validación del equipo.

\section{EI CEF}

El desarrollo del Caracterizador Electrónico de Fibras (CEF), denominado Fiber EC, se basó en la captura de imágenes de fibras dispersas mediante un componente óptico, que mediante un software propietario 
son procesadas utilizando tecnología de visión artificial que involucra: conversión de las imágenes a escala de grises (preprocesadorealce), segmentación y suavizado, binarización de imágenes para distinguir fibra y fondo (1=muestra, $0=$ fondo), operaciones morfológicas de erosión y dilatación (para eliminar restos no deseados y homogenización de las imágenes), y esqueletización y podado de las imágenes de las fibras, para luego utilizar la transformada de «Hough», con el fin de hallar rectas a lo largo de la curvatura de las muestras de imágenes de fibra. Finalmente se procedió a la detección de bordes para definir la distancia del diámetro de la fibra expresado en pixeles. A fin de captar la mayor cantidad de imágenes de fibras dentro del componente mecánico se consideró una parte móvil donde se colocaron las muestras que permitía realizar un barrido en dos direcciones $\mathrm{X} \mathrm{e}$ Y, gobernado por el componente electrónico.

El CEF se trabajó en modo de fragmentos (para uso en laboratorio), siguiendo el procedimiento de IWTO 47 (IWTO-47, 2007), para lo cual fragmentos de fibras obtenidas mediante un cortador de fibras fueron esparcidos y colocados en un porta-fibras. También se utilizó en modo de mechas para evaluar su uso en condiciones de campo, de acuerdo al procedimiento describo por Quispe et al. (2017).

\section{Muestras de Lanas y Fibras}

Para la calibración, validación y evaluación del CEF se utilizaron ocho muestras patrones de tops de lana de ovinos de diámetros, desviación estándar y coeficientes de variación conocidos; siete muestras patrones de tops de mohair de diámetro conocido, y seis muestras de fibras de vicuñas medidas en el Laserscan, cuyos diámetros fueron 13.5, $13.8,13.9,14.3,14.4$ y $14.5 \mu \mathrm{m}$. Para la evaluación del uso potencial del CEF en otros tipos de fibras, se utilizaron muestras de fibras lavadas de cachemira y tops de fibras de alpacas. Las muestras patones fueron obtenidas del Laboratorio de Fibras Textiles del INTA, Bariloche, y las mediciones se realizaron en modo de fragmentos.
Adicionalmente, se utilizaron 299 muestras de fibra sucia de alpacas obtenidas del Centro de Investigación y Producción de Camélidos Sudamericanos (CIPCS), Lachocc, de la UNH, y las mediciones se realizaron en modo de mechas.

\section{Calibración y Validación del CEF}

Previa a la calibración del CEF, se realizó una ponderación para la transformación de pixeles a micrones, mediante la medición de una muestra patrón de $18.47 \mu \mathrm{m}$. La ponderación se realizó preparando una muestra de fragmentos de $2 \mathrm{~mm}$ de top de lana de ovino en un porta-fibras de vidrio de $7 \mathrm{x} 9 \mathrm{~cm}$, que se colocó en el portamuestras, para iniciar la medición con el CEF. Luego se midió la misma muestra, comprobándose que efectivamente se repetía el mismo valor de 18.47 $\mu \mathrm{m}$.

Seguidamente se prepararon cuatro submuestras con cada uno de los ocho patrones de tops de lana de ovinos, midiéndose cada uno de ellos en el CEF. Luego se obtuvieron los promedios de cada muestra patrón (que no concordaban con los valores reales) y se realizó el ploteo con los valores conocidos de cada muestra patrón, estableciéndose una ecuación de regresión lineal que fue evaluada mediante el coeficiente de regresión y correlación. La ecuación fue introducida al algoritmo del CEF, obteniendo así un equipo calibrado.

La validación del CEF para muestras de fragmentos de tops de lana de ovino se realizó midiendo nuevamente cuatro submuestras de cada uno de los ocho tops patrones, y posteriormente verificando la coincidencia o cercanía de los promedios obtenidos con los valores conocidos de cada top patrón. Adicionalmente, las mismas submuestras de tops fueron evaluadas con el OFDA2000 en modo 100, a fin de comparar las mediciones, precisión y exactitud de la media de diámetro de fibra (MDF) entre ambos equipos. Finalmente, se realizaron 
mediciones de la MDF en muestras de 21 tops patrones de lana de ovinos en el CEF y el equipo Laserscan a fin de evaluar la relación de las mediciones de la MDF obtenidas en entre ambos equipos.

Para uso en fibras de mohair, la calibración del CEF incluyó el promedio de cuatro submuestras de un patrón de top de mohair de $43.1 \mu \mathrm{m}$; lo cual fue adicionado a los promedios obtenidos anteriormente de los ocho patrones de tops de lana de ovinos. El ploteo se realizó nuevamente con los valores conocidos de cada muestra patrón, estableciéndose otra ecuación de regresión lineal, para el uso del CEF en la evaluación de mohair. La validación se realizó midiendo cuatro submuestras de cada uno de los siete tops patrones de mohair, y posteriormente verificando la coincidencia o cercanía de los promedios obtenidos con los valores conocidos de cada top patrón de mohair.

Para la evaluación de fibras de vicuñas, la calibración del CEF incluyó promedios de cuatro submuestras de cada una de las seis muestras patrones medidas previamente con el Laserscan; los que fueron adicionados a los promedios obtenidos anteriormente de los ocho patrones de tops de lana de ovinos. Se realizó nuevamente el ploteo con los valores conocidos de cada muestra patrón, estableciéndose otra ecuación de regresión lineal que fue incluido en el algoritmo del CEF para su uso en la evaluación de fibras de vicuñas. Para este caso, debido que las fibras de vicuñas son finas, se incluyó en el algoritmo del CEF la condición de no considerar fibras mayores a $22 \mu \mathrm{m}$, para así tener resultados más precisos, pero a la vez evitando la medición de pelos existentes en vellones de vicuñas. La validación se realizó de forma similar al del mohair, pero en este caso se consideraron cuatro submuestras de cada uno de las seis muestras lavadas de fibras de vicuñas, cuyas medias de diámetro habían sido estimadas mediante el Laserscan.
Posteriormente, utilizando la ecuación para tops de lana de ovinos y para evaluar el potencial uso del CEF con fibras de alpacas, se realizaron mediciones alternativas de 30 tops de fibras de alpacas, tanto en el OFDA 2000 modo 100 como en el CEF en modo de fragmentos.

Finalmente, para evaluar el potencial uso del CEF en condiciones de campo, se realizaron mediciones de 299 muestras de mechas de fibras de alpacas, las cuales fueron medidas en el OFDA2000 modo mechas y en el CEF modo mechas, lo que permitió evaluar el grado de relación de resultados entre ambos equipos.

\section{Análisis Estadístico}

Se utilizaron estadísticos descriptivos como promedios, desviación estándar e intervalos de confianza; adicionalmente, se hizo uso de gráficos de ploteo y ajuste lineal, para lo cual se utilizó el paquete estadístico R v. 3.1.1 (R Core Team, 2016). La precisión fue evaluada mediante la desviación estándar y los intervalos de confianza a nivel de $95 \%$, mientras que la exactitud se determinó mediante la diferencia absoluta entre los promedios de las mediciones de cuatro submuestras con el valor real de cada muestra patrón utilizado.

Para la comparación de la precisión y exactitud entre el OFDA2000 y el CEF se realizó la prueba de «t» para muestras pareadas. Asimismo, el programa VCE v. 5.0 (Neumaier y Groeneveld, 1998) se utilizó para la solución del modelo aleatorio propuesto, mediante el procedimiento de máxima verosimilitud restringida (REML), para la estimación de la repetibilidad de cinco características que mide el CEF. Finalmente, el coeficiente de correlación de Pearson se utilizó para evaluar la relación de las mediciones del CEF con el Laserscan y OFDA 2000. 


\section{Resultados y Discusión}

\section{EI CEF}

Esquemáticamente, el caracterizador electrónico portátil de fibras consta de una fuente de iluminación que permite visualizar la muestra de fibra, la cual es magnificada mediante una lente de aumento unido con espaciadores a un detector de imagen que captura y envía información a la computadora, donde es procesada mediante tecnología de visión artificial para el cálculo del diámetro de fibra y derivada en base a fórmulas a otras características tecnológicas (Figura 1). La conformación y procedimiento descritos también son utilizados por los prototipos desarrollados por Qi et al. (1995), Li et al. (2002), Baltuano et al. (2005) y Brims (Australia Patente N. ${ }^{\circ}$ W0 2007/025350 A1, 2006), con algunas diferencias marcadas.

Los cuatro componentes del CEF son: a) Electrónico, que controla cuatro motores para deslizar piezas del equipo en los ejes « $\langle\mathrm{X}\rangle$, «y», «Z» de forma adecuada y sincronizada; además, controla la iluminación, los sensores de humedad y temperatura y envía datos a la computadora; b) Mecánico, en la que se consideran elementos estáticos y otros móviles, siendo los principales la mesa de coordenadas $\langle x\rangle$ e «y», soporte del microscopio, portaobjetos, porta-muestras, carcasa, motores paso a paso y soportes, entre otros; c) Óptico, conformado por una cámara digital, lentes de aumento y la iluminación, que en su conjunto viene a ser un microscopio digital personalizado; d) Software, constituido por el programa de procesamiento digital de imágenes desarrollado e instalado en una computadora que permite evaluar la calidad de las fibras de origen animal. Estos componentes se encuentran arreglados dentro de un maletín de forma paralelepípedo, elaborado de un material resistente a golpes y la corrosión, cuya configuración es hermética, y tiene dos manijas para poder transportarla a los lugares de trabajo (Figura 2).

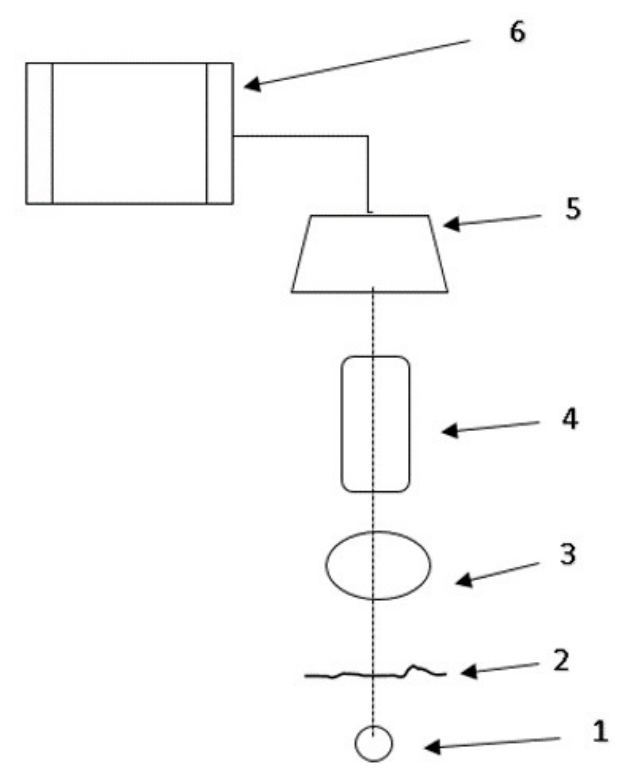

Figura 1. Diagrama esquemático del Caracterizador Electrónico de fibras (CEF): 1) Fuente de iluminación, 2) Muestra de fibra a analizar, 3) Lente de aumento, 4) Espaciador, 5) Detector de imagen, 6) Computadora

El equipo tiene la capacidad de trabajo en campo, en condiciones de altitud hasta 5300 metros sobre el nivel del mar y a temperaturas hasta de $-10{ }^{\circ} \mathrm{C}$, de medir fibras en diferentes rangos promedios de diámetro, existiendo procedimientos específicos para la evaluación de fibras de vicuñas, alpacas, llamas, ovinos, cachemira, mohair, pelo de vacuno y pelo de humanos, con capacidad de incorporación de procedimientos para otros tipos de fibras.

Mejoras al estado de arte del CEF están referidas a su portabilidad, especificidad para la medición de determinadas fibras gruesas y delgadas, potencialidad de medición en muestras de fibras poco disgregadas y visualización nítida de imágenes de las fibras que son medidas en tiempo real, debido a interacción de sus componentes tales como detector de imagen de alta velocidad, obturador de detector de imagen, lente y tornillo de 


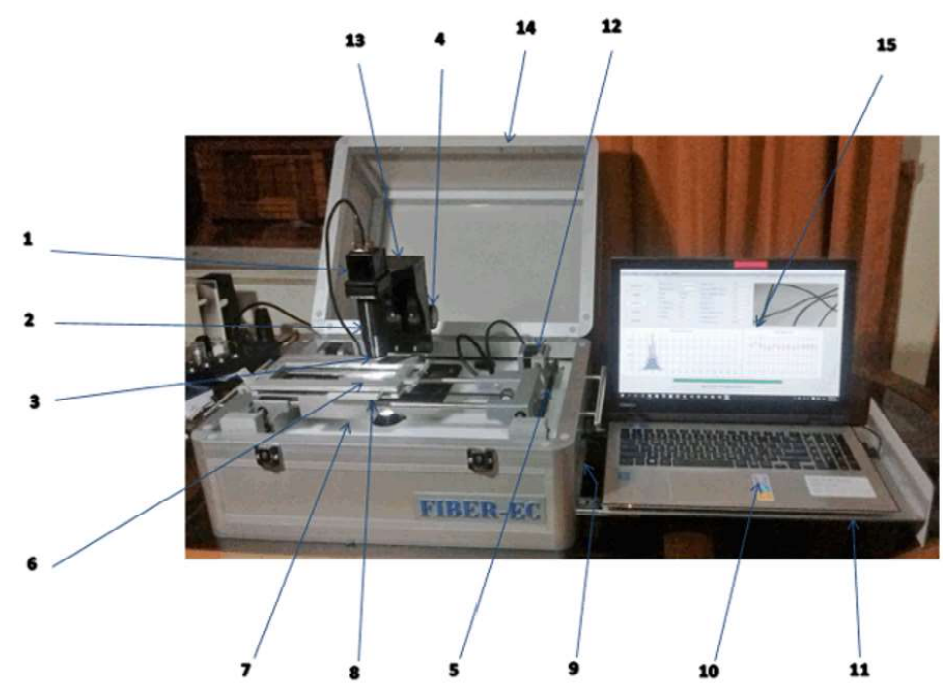

Figura 2. Equipo Caracterizador Electrónico de fibras (CEF): 1) Detector de imagen, 2) Espaciador, 3) Objetivo o lente de aumento (permite visualizar las imágenes con nitidez), 4) Tornillo de enfoque, 5) Faja de trasmisión, 6) Portaobjeto, 7) Base de la mesa de coordenadas, 8) Mesa de coordenadas, 9) Circuito electrónico, 10) Computadora, 11) Tablero deslizante del ordenador, 12) Porta motor, 13) Soporte del microscopio digital (cámara + objetivo), 14) Cubierta superior del Caracterizador electrónico portátil de fibra, 15) Interface Gráfica del usuario (GUI)

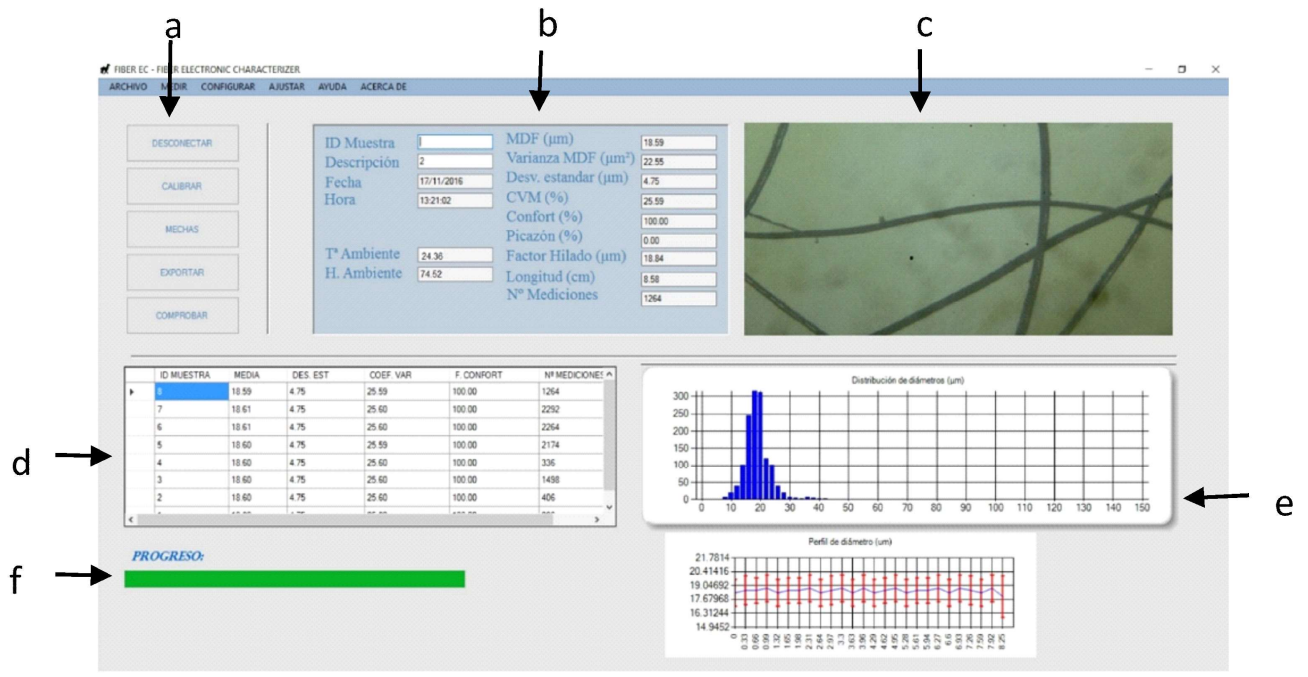

Figura 3. Interfaz gráfica del usuario del Caracterizador Electrónico de Fibras. Obsérvese que las fibras que son evaluadas se visualizan nítidamente. a, b, c, d, e, f: corresponden a la primera, segunda, tercera, cuarta, quinta y sexta ventana respectivamente 
enfoque manual. Adicionalmente, permite la preparación de muestras bajo condiciones de campo, permitiendo llevar al equipo a los lugares de producción durante la esquila, comercialización o acopio de fibras. Particularidad adicional del equipo es su capacidad para la medición de fibras gruesas (pelos) en forma automática, también en forma precisa y exacta, debido a la implementación de una calibración rápida con una muestra patrón con rangos de diámetro específicos.

La interfaz gráfica del usuario contiene íconos para controlar el hardware y realizar la evaluación de las fibras. En la primera ventana se encuentran iconos que permite ponderar el diámetro de las fibras con el patrón estándar, iniciar el proceso de barrido y exportar los datos e imágenes a Excel, mientras que en la segunda ventana se permite el ingreso de la identificación, descripción de la muestra a evaluar y, adicionalmente, muestra los resultados de la evaluación, así como el monitoreo de la temperatura ambiental y humedad relativa. En la tercera ventana se muestran las imágenes de las fibras que van siendo evaluadas. La cuarta ventana muestra los resultados de las nueve últimas muestras analizadas. En la quinta ventana se visualiza el histograma y el perfil del diámetro de fibra, y en la sexta ventana se puede observar el progreso de la evaluación de la muestra en tiempo real (Figura 3).

Ante la importancia que tiene el incremento del número de mediciones para la obtención de tolerancia bajas (ASTM, 2001), el CEF tiene la capacidad de realizar alrededor 50000 mediciones de fibras en 30 segundos por muestra, pero al descartar mediciones con problemas de cruce o mal enfocadas, permite alcanzar entre 8 y 9 mil mediciones válidas cuando se utiliza una computadora con procesador que tiene una velocidad mínima de $2.6 \mathrm{GHz}$ a 8 núcleos de la computadora, mientras que las mediciones válidas disminuyen entre 2 y 3 mil mediciones cuando la velocidad de procesamiento es de $1.5 \mathrm{GHz}$ a 4 núcleos.

\section{Calibración y Validación del CEF (lanas y fibras de ovinos, mohair y vicuñas)}

Los modelos de regresión lineal simple obtenidos de la medición de lana de ovinos, mohair y vicuñas para la calibración del CEF se observan en el Cuadro 1. Los modelos resultantes (ovinos: $\mathrm{y}=-7.145+1.387^{*} \mathrm{x}$; mohair: $\mathrm{y}=-5.889+1.3330 * \mathrm{x}$; vicuñas: $\mathrm{y}=-5.083+1.228 * \mathrm{x}$ ) son óptimos debido a que explican las observaciones casi al 100\% (coeficiente de determinación $=0.999$ ). Asimismo, la relación entre los datos reales de las muestras patrones y los obtenidos en el equipo sin validar es muy buena (Figura 4), lo cual se vislumbra en el coeficiente de correlación que viene ser cercano a 1 (Cuadro 2). Cada uno de estos modelos fue incorporado en el software del CEF, quedando listo el equipo para la evaluación de esos tipos de fibras. La utilización de regresiones lineales simples para la calibración es utilizada por equipos comerciales como el OFDA y el Laserscan (IWTO, 2013), los cuales obtienen valores de correlación similares a los obtenidos en este estudio.

Al obtener los modelos de regresión de calibración previa conversión de pixeles a micras en base a un patrón (top de lana de ovino) de $18.47 \mu \mathrm{m}$, y luego pareando los valores obtenidos en el CEF sin calibrar con los valores de los patrones, se requiere de dos cálculos, los cuales podrían incidir en pérdida de la precisión, por lo que en próximas versiones podrían considerarse un solo paso; es decir, pareando directamente los pixeles obtenidos en el CEF con los valores de los patrones de tops de lanas, tal como fue realizado por Qi et al. (1995) cuando calibraron su prototipo denominado 'Sistema de Análisis Automático de Imágenes' de la Estación Experimental de Agricultura de Texas que también permite evaluar fibras de animales.

En torno a la validación del CEF calibrado con muestras patrones de tops de ovinos, los valores promedios obtenidos de la finura, desviación estándar y coeficiente de variación son similares a los valores de los 
Cuadro 1. Regresiones utilizadas para la calibración del Caracterizador Electrónico de Fibras para la evaluación de tops de lanas de ovinos y fibras de mohair y vicuñas

\begin{tabular}{clcccc}
\hline Especie & & Estimados & Error estándar & $\mathrm{t}$ & Significancia \\
\hline Ovinos & Intercepto & -7.145 & 0.572 & -12.494 & $\mathrm{p}<0.001$ \\
& Regresión & 1.387 & 0.024 & 58.548 & $\mathrm{p}<0.001$ \\
\multirow{3}{*}{ Mohair } & Intercepto & -5.889 & 0.718 & -8.201 & $\mathrm{p}<0.001$ \\
& Regresión & 1.330 & 0.028 & 48.065 & $\mathrm{p}<0.001$ \\
\multirow{2}{*}{ Vicuña } & Intercepto & -5.083 & 0.727 & -6.995 & $\mathrm{p}<0.001$ \\
& Regresión & 1.228 & 0.026 & 46.917 & $\mathrm{p}<0.001$ \\
\hline
\end{tabular}

Cuadro 2. Correlaciones entre las muestras patrones y los obtenidos en el Caracterizador Electrónico de Fibras antes de la calibración para tops de lanas de ovinos y fibras de mohair y vicuña

\begin{tabular}{ccccc}
\hline \multirow{2}{*}{ Fibra animal } & $\begin{array}{c}\text { Correlación de } \\
\text { Pearson }\end{array}$ & \multicolumn{2}{c}{ Intervalo de confianza (95\%) } & \multirow{2}{*}{ Significancia } \\
\cline { 3 - 4 } & 0.999 & Inferior & Superior & \\
\hline Ovinos & 0.998 & 0.995 & 1.000 & $\mathrm{p}<0.001$ \\
Mohair & 0.992 & 0.985 & 1.000 & $\mathrm{p}<0.001$ \\
Vicuña & & & 0.996 & $\mathrm{p}<0.001$ \\
\hline
\end{tabular}

patrones (Cuadro 3), lo cual muestra la buena exactitud del equipo. De otro lado, las desviaciones estándar de las cuatro mediciones para diámetro de fibra, desviación estándar, coeficiente de variación y factor de confort varían entre 0.49 y $0.11 \mu \mathrm{m}, 0.06$ y $0.24 \mu \mathrm{m}$, 0.028 y $1.03 \%$ y 0.05 y $2.23 \%$, respectivamente (Cuadro 3) e indican la precisión del equipo para los diferentes rangos de diámetros de fibras, resultando las desviaciones estándar similares a los obtenidos para el Laserscan de acuerdo a IWTO-12 (IWTO12, 2003). Asimismo, los resultados de promedios de desviaciones estándar van incrementándose conforme se incrementa el diámetro promedio de las fibras medidas, variando desde 3.21 hasta $6.61 \mu \mathrm{m}$ para fibras con diámetros de 15.71 hasta $35.37 \mu \mathrm{m}$, lo cual se encuentra acorde con el método de micro proyección (ASTM, 2001), lo que permite deducir que la precisión en fibras grue- sas es menor que cuando se analizan fibras finas.

Otra evaluación de exactitud y precisión del CEF para análisis de muestras de lana de ovinos se muestra en el Cuadro 4, donde se puede visualizar que la exactitud del CEF resulta ser mejor que el OFDA2000 en modo 100 bajo la norma IWTO-47 (IWTO-47, 2007). Cuando se evalúan fibras entre 15 y $35 \mu \mathrm{m}$, los resultados con el CEF de la media de diámetro de fibra se desvían de los valores reales entre 0.01 y 0.54 con una media de $0.16 \mu \mathrm{m}$, mientras que con el OFDA2000 en modo 100 se desvían entre 0.01 y 0.60 , con una media de $0.26 \mu \mathrm{m}$ $(\mathrm{p}=0.04)$. Asimismo, cuando se analizan los indicadores de precisión de la finura, la desviación estándar varía entre 0.11 y 0.49 en el CEF y de 0.11 y 0.64 para el OFDA2000 en modo 100 , concordando los mismos valores 
Cuadro 3. Evaluación de muestras de top de lana de ovinos, considerando muestras patrón de diámetro conocido, utilizando el Caracterizador Electrónico de Fibras calibrado

\begin{tabular}{|c|c|c|c|c|c|c|c|}
\hline \multirow{2}{*}{ Característica } & \multirow{2}{*}{$\begin{array}{c}\mathrm{MDF} / \mathrm{DE} / \mathrm{CV}- \\
\text { patrón }\end{array}$} & \multicolumn{4}{|c|}{ Mediciones } & \multirow{2}{*}{ Media } & \multirow{2}{*}{ D.E. } \\
\hline & & $1^{\mathrm{a}}$ & $2^{\mathrm{a}}$ & $3^{a}$ & $4^{\mathrm{a}}$ & & \\
\hline $\begin{array}{l}\text { Media de diámetro } \\
\text { de fibra (MDF) }\end{array}$ & $\begin{array}{l}15.71 \\
18.47 \\
20.66 \\
24.29 \\
26.57 \\
31.65 \\
32.60 \\
35.37\end{array}$ & $\begin{array}{l}15.57 \\
18.51 \\
20.71 \\
24.37 \\
26.24 \\
32.23 \\
32.65 \\
35.06\end{array}$ & $\begin{array}{l}15.85 \\
18.64 \\
20.57 \\
24.12 \\
27.03 \\
31.85 \\
32.23 \\
34.60\end{array}$ & $\begin{array}{l}15.54 \\
18.43 \\
20.51 \\
24.67 \\
26.73 \\
32.07 \\
33.22 \\
35.08\end{array}$ & $\begin{array}{l}15.26 \\
18.39 \\
20.99 \\
24.26 \\
25.95 \\
31.91 \\
32.32 \\
34.58\end{array}$ & $\begin{array}{l}15.56 \\
18.49 \\
20.70 \\
24.35 \\
26.49 \\
32.01 \\
32.61 \\
34.83\end{array}$ & $\begin{array}{l}0.244 \\
0.108 \\
0.218 \\
0.232 \\
0.486 \\
0.172 \\
0.446 \\
0.276\end{array}$ \\
\hline $\begin{array}{l}\text { Desviación } \\
\text { estándar de la } \\
\text { MDF (DEMDF) }\end{array}$ & $\begin{array}{l}3.14 \\
3.86 \\
4.19 \\
5.45 \\
6.19 \\
7.02 \\
8.34 \\
8.87\end{array}$ & $\begin{array}{l}3.24 \\
3.99 \\
3.84 \\
4.70 \\
5.04 \\
5.42 \\
6.41 \\
6.64\end{array}$ & $\begin{array}{l}3.19 \\
3.67 \\
3.61 \\
5.19 \\
5.30 \\
5.47 \\
6.45 \\
6.50\end{array}$ & $\begin{array}{l}3.11 \\
3.79 \\
3.63 \\
4.87 \\
5.13 \\
5.44 \\
6.50 \\
6.38\end{array}$ & $\begin{array}{l}3.30 \\
3.76 \\
3.82 \\
4.77 \\
5.10 \\
5.76 \\
6.55 \\
6.93\end{array}$ & $\begin{array}{l}3.21 \\
3.80 \\
3.73 \\
4.88 \\
5.14 \\
5.52 \\
6.48 \\
6.61\end{array}$ & $\begin{array}{l}0.080 \\
0.133 \\
0.122 \\
0.215 \\
0.112 \\
0.161 \\
0.061 \\
0.236\end{array}$ \\
\hline $\begin{array}{l}\text { Coeficiente de } \\
\text { variación de MDF } \\
\text { (CVMDF) }\end{array}$ & $\begin{array}{l}20.00 \\
20.89 \\
20.69 \\
22.43 \\
23.29 \\
22.18 \\
25.57 \\
25.07\end{array}$ & $\begin{array}{l}19.78 \\
21.54 \\
19.11 \\
20.69 \\
20.94 \\
19.10 \\
22.32 \\
21.82\end{array}$ & $\begin{array}{l}19.26 \\
19.74 \\
18.06 \\
23.01 \\
21.50 \\
19.44 \\
22.72 \\
21.59\end{array}$ & $\begin{array}{l}19.03 \\
20.56 \\
18.23 \\
21.25 \\
21.00 \\
19.22 \\
22.34 \\
20.96\end{array}$ & $\begin{array}{l}20.45 \\
20.44 \\
18.85 \\
21.07 \\
21.36 \\
20.46 \\
23.00 \\
23.03\end{array}$ & $\begin{array}{l}19.63 \\
20.57 \\
18.56 \\
21.50 \\
21.20 \\
19.56 \\
22.60 \\
21.85\end{array}$ & $\begin{array}{l}0.629 \\
0.743 \\
0.501 \\
1.032 \\
0.276 \\
0.620 \\
0.328 \\
0.865\end{array}$ \\
\hline $\begin{array}{l}\text { Factor de confort } \\
\text { (FC) }\end{array}$ & & $\begin{array}{l}99.27 \\
98.23 \\
98.26 \\
92.87 \\
87.36 \\
60.83 \\
56.80 \\
47.83\end{array}$ & $\begin{array}{l}99.17 \\
98.96 \\
98.76 \\
91.67 \\
83.72 \\
63.18 \\
59.65 \\
50.09\end{array}$ & $\begin{array}{l}99.19 \\
98.77 \\
98.70 \\
91.08 \\
85.36 \\
61.59 \\
53.83 \\
46.56\end{array}$ & $\begin{array}{l}99.22 \\
98.73 \\
98.27 \\
91.98 \\
88.80 \\
62.12 \\
58.30 \\
47.21\end{array}$ & $\begin{array}{l}99.21 \\
98.67 \\
98.50 \\
91.90 \\
86.31 \\
61.93 \\
57.14 \\
47.92\end{array}$ & $\begin{array}{l}0.045 \\
0.314 \\
0.271 \\
0.745 \\
2.230 \\
0.988 \\
2.500 \\
1.532\end{array}$ \\
\hline
\end{tabular}

para el IC al 95\% para cada equipo ( $\mathrm{p}=0.26)$, lo que indica que ambos equipos tienen la misma precisión.

La relación entre el CEF y el Laserscan (Figura 5) presenta un coeficiente de regresión de $1.07 \mu \mathrm{m}$ y un coeficiente de correlación de Pearson de 0.99 , valores muy cerca- nos a 1 , que indica que los dos equipos obtienen resultados similares al evaluar lana de ovinos.

Los valores de intervalo de confianza al 95\% para el CEF no solo están dentro del rango tolerable para el OFDA, según la norma IWTO-47 (IWTO-47, 2003), sino que 


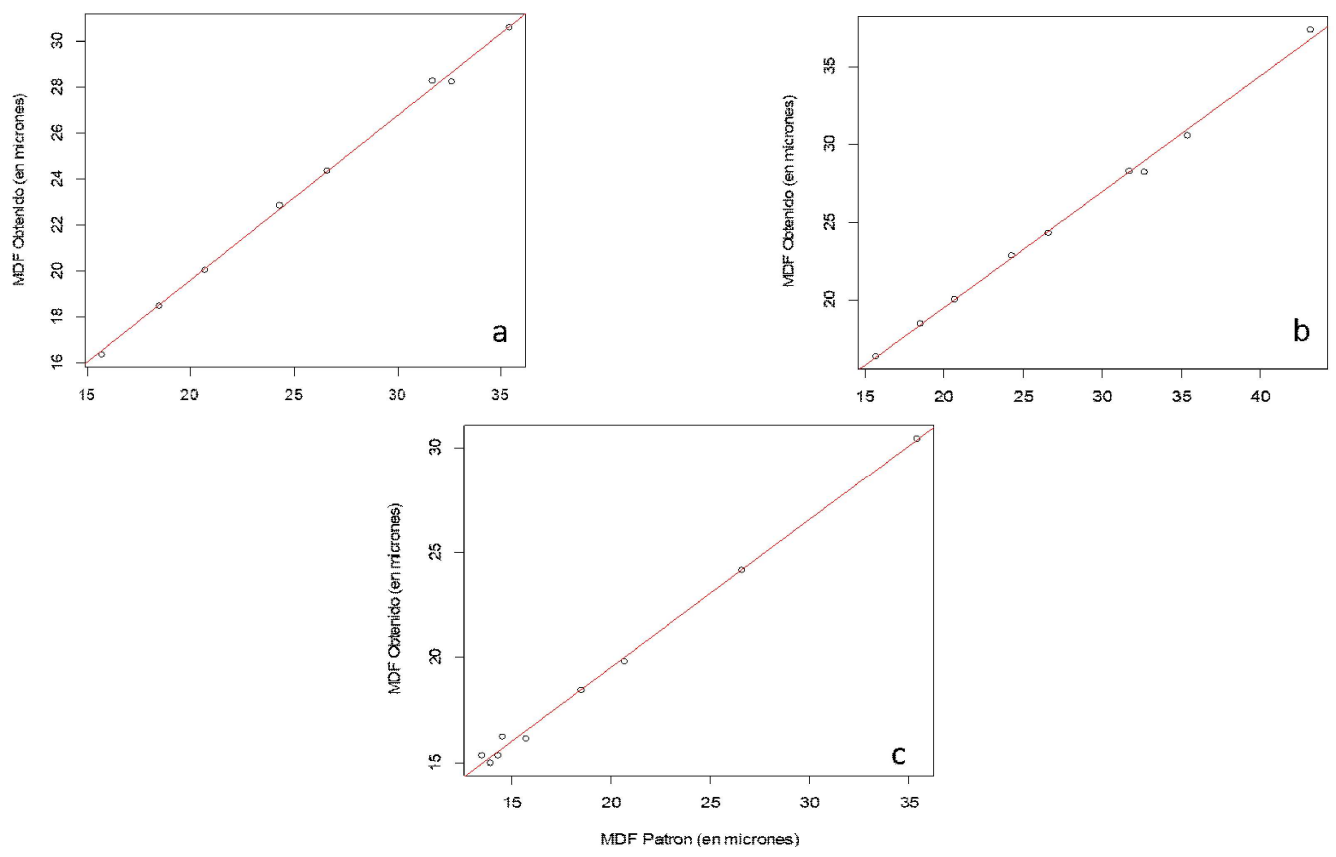

Figura 4. Gráficos de puntos y ajuste lineal de la media de diámetro de fibra (MDF) de patrones de tops de lana de ovinos (a), fibras de mohair (b) y vicuñas (c) con las obtenidas en el Caracterizador Electrónico de Fibras, previa a su calibración. La ecuación lineal de estos gráficos se utilizó para la calibración

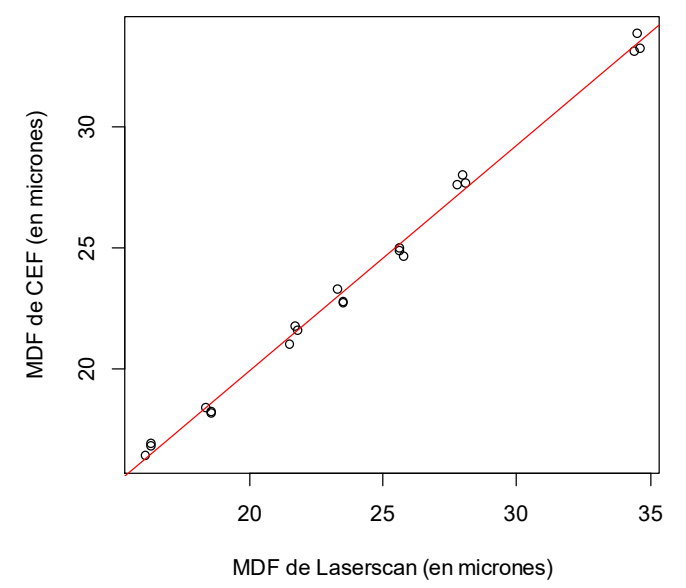

Figura 5. Gráfico de puntos y ajuste lineal de la MDF de fragmentos de tops de lana de ovinos obtenidas en el Laserscan y el Caracterizador Electrónico de Fibras. La ecuación de regresión es: MDF Laserscan $=$ $-1.185+1.065 *$ MDF CEF. El Coef. de correlación de Pearson es 0.998 también se encuentran dentro de los rangos tolerables indicados en la norma IWTO-12 (IWTO-12, 2003) para el Laserscan, IWTO8 (IWTO-8, 2004) para microscopio de proyección e IWTO-28 (IWTO-28, 2000) para el Airflow (Cottle y Baxter, 2015). Estas comparaciones refuerzan la adecuada precisión y exactitud que tiene el CEF en la evaluación de lanas de ovinos.

Los cuadros 5 y 6 muestran la evaluación del CEF para análisis de fibras de mohair y vicuñas. En forma similar a la evaluación de tops de lana de ovinos, los promedios del diámetro de fibras de mohair obtenidos con el CEF resultan ser cercanos a los valores reales de los tops patrones de mohair, mientras que la desviación estándar obtenido de las cuatro mediciones de las submuestras de cada muestra patrón resultan ser bajas, variando entre 0.16 a $1.10 \mu \mathrm{m}$ para diámetro de 
Cuadro 4. Desviación estándar, intervalo de confianza al 95\% (IC) y exactitud ${ }^{1}$ de resultados de la evaluación de la media de diámetro de fibra (MDF) en muestras de top de lana de ovino, según el Caracterizador Electrónico de Fibras (CEF) y el OFDA 2000 utilizado en modo 100

\begin{tabular}{ccccccccc}
\hline \multirow{2}{*}{ MDF-Patrón n } & \multicolumn{4}{c}{ CEF } & \multicolumn{4}{c}{ OFDA 2000 en modo 100 } \\
\cline { 2 - 9 } & Media & D.E. & IC & Exactitud & Media & D.E. & IC & Exactitud \\
\hline 15.71 & 15.56 & 0.244 & 0.159 & 0.154 & 15.30 & 0.119 & 0.078 & 0.413 \\
18.47 & 18.49 & 0.108 & 0.071 & 0.023 & 18.27 & 0.085 & 0.055 & 0.203 \\
20.66 & 20.70 & 0.218 & 0.142 & 0.036 & 20.50 & 0.119 & 0.078 & 0.160 \\
24.29 & 24.35 & 0.232 & 0.152 & 0.064 & 24.19 & 0.105 & 0.068 & 0.105 \\
26.57 & 26.49 & 0.486 & 0.318 & 0.084 & 26.37 & 0.153 & 0.100 & 0.200 \\
31.65 & 32.01 & 0.172 & 0.112 & 0.363 & 31.66 & 0.131 & 0.085 & 0.010 \\
32.60 & 32.61 & 0.446 & 0.292 & 0.006 & 32.01 & 0.402 & 0.263 & 0.595 \\
35.37 & 34.83 & 0.276 & 0.180 & 0.538 & 34.96 & 0.638 & 0.417 & 0.407 \\
\hline
\end{tabular}

${ }^{1}$ Diferencia absoluta de la MDF de la muestra patrón y el promedio obtenido con el CEF

fibra, entre 0.06 y $1.11 \mu \mathrm{m}$ para la desviación estándar del diámetro de fibra, entre $0.28 \mathrm{y}$ $3.49 \%$ para el coeficiente de variación del diámetro de fibra y entre 0.41 y $3.60 \%$ para el factor de confort. De otro lado cuando se trabaja con fibras de vicuñas, los valores promedios de diámetro de fibra obtenidos con el CEF son cercanos a los valores obtenidos con el Laserscan, mientras que las desviaciones estándar para cada una de las características evaluadas varían entre 0.10 y $0.36 \mu \mathrm{m}$ para diámetro de fibra, entre 0.06 y $0.23 \mu \mathrm{m}$ para la desviación estándar del diámetro de fibra, entre 0.20 y $0.83 \%$ para el coeficiente de variación del diámetro de fibra, resultando 0 para el factor de confort. Estos resultados indican una buena precisión y exactitud del CEF cuando se analizan fibras de mohair y vicuñas.

En la evaluación de fibras de mohair, a medida que se incrementa el diámetro de las fibras, también van en aumento las desviaciones estándar, ocurriendo lo contrario con respecto al factor de confort, resultando indiferente con el coeficiente de variación. Así, cuando el diámetro del patrón es $22.3 \mu \mathrm{m}$ la desviación estándar es cercana a $6 \mu \mathrm{m}$, que se incrementa casi en $5 \mu \mathrm{m}$ cuando el diámetro es de $43.10 \mu \mathrm{m}$, lo que resulta concordante con lo indicado por ASTM (2001); sin embargo, el factor de confort disminuye desde cerca de 93 hasta un valor cercano a $22 \%$. Estas relaciones no se observan claramente en la evaluación de fibras de vicuñas, lo cual probablemente se deba a que el rango de diámetro de fibras medidas es reducido (desde 13.5 hasta $14.5 \mu \mathrm{m}$ ); resultados concordantes con el estudio de Quispe et al. (2010), quienes obtienen una correlación de 0.24 no significativa entre el diámetro y la deviación estándar de fibras de vicuñas.

\section{Precisión y Exactitud del CEF (fibras de mohair y vicuñas)}

La evaluación de la precisión y exactitud del CEF para fibras de mohair se muestra en el Cuadro 7. La exactitud para la MDF varía entre 0.08 y $0.57 \mu \mathrm{m}$ con una media de $0.34 \mu \mathrm{m}$. Con respecto a la precisión, la desviación estándar varía entre 0.16 y 0.52 con una media de 0.47 , y para el intervalo de confianza varía entre 0.16 y 1.07 ; resultados que se encuentran dentro de los valores tolerables exigidos por IWTO y ASTM cuando se 
Cuadro 5. Evaluación de muestras de top de fibras de mohair, considerando las muestras patrón de diámetro conocido, utilizando el Caracterizador Electrónico de Fibras calibrado

\begin{tabular}{|c|c|c|c|c|c|c|c|}
\hline \multirow{2}{*}{ Característica } & \multirow{2}{*}{ MDF-patrón } & \multicolumn{4}{|c|}{ Mediciones } & \multirow{2}{*}{ Media } & \multirow{2}{*}{ D.E. } \\
\hline & & $1^{\mathrm{a}}$ & $2^{\mathrm{a}}$ & $3^{\mathrm{a}}$ & $4^{\mathrm{a}}$ & & \\
\hline \multirow{7}{*}{$\begin{array}{l}\text { Media de diámetro } \\
\text { de fibra (MDF) }\end{array}$} & 22.30 & 22.60 & 22.20 & 21.78 & 21.75 & 22.08 & 0.402 \\
\hline & 25.50 & 26.40 & 25.58 & 26.16 & 25.64 & 25.94 & 0.400 \\
\hline & 27.10 & 27.20 & 27.12 & 26.90 & 26.87 & 27.02 & 0.160 \\
\hline & 30.30 & 31.52 & 30.58 & 30.47 & 31.26 & 30.96 & 0.513 \\
\hline & 34.30 & 34.77 & 35.26 & 34.71 & 34.71 & 34.86 & 0.266 \\
\hline & 37.80 & 37.93 & 38.06 & 37.07 & 37.29 & 37.58 & 0.483 \\
\hline & 43.10 & 43.78 & 44.61 & 42.45 & 42.35 & 43.30 & 1.091 \\
\hline \multirow{7}{*}{$\begin{array}{l}\text { Desviación } \\
\text { estándar de la } \\
\text { MDF (DEMDF) }\end{array}$} & 22.30 & 6.08 & 6.09 & 5.91 & 5.72 & 5.95 & 0.171 \\
\hline & 25.50 & 5.91 & 6.16 & 6.05 & 5.78 & 5.97 & 0.163 \\
\hline & 27.10 & 5.62 & 5.72 & 5.61 & 5.71 & 5.66 & 0.059 \\
\hline & 30.30 & 4.91 & 5.00 & 5.35 & 5.36 & 5.16 & 0.232 \\
\hline & 34.30 & 7.51 & 7.33 & 7.39 & 7.36 & 7.40 & 0.080 \\
\hline & 37.80 & 7.33 & 7.44 & 7.22 & 7.54 & 7.38 & 0.138 \\
\hline & 43.10 & 9.62 & 9.27 & 9.92 & 11.75 & 10.14 & 1.106 \\
\hline \multirow{7}{*}{$\begin{array}{l}\text { Coeficiente de } \\
\text { variación de MDF } \\
\text { (CVMDF) }\end{array}$} & 22.30 & 28.50 & 28.94 & 28.54 & 27.67 & 28.41 & 0.535 \\
\hline & 25.50 & 24.38 & 26.10 & 25.15 & 24.47 & 25.02 & 0.792 \\
\hline & 27.10 & 22.63 & 23.08 & 22.78 & 23.22 & 22.93 & 0.272 \\
\hline & 30.30 & 17.47 & 18.26 & 19.59 & 19.20 & 18.63 & 0.951 \\
\hline & 34.30 & 24.56 & 23.68 & 24.19 & 24.10 & 24.13 & 0.363 \\
\hline & 37.80 & 22.22 & 22.50 & 22.34 & 23.20 & 22.56 & 0.439 \\
\hline & 43.10 & 25.7 & 24.34 & 27.24 & 32.32 & 27.40 & 3.487 \\
\hline \multirow{7}{*}{$\begin{array}{l}\text { Factor de confort } \\
\text { (FC) }\end{array}$} & 22.30 & 91.55 & 91.59 & 93.28 & 93.39 & 92.45 & 1.021 \\
\hline & 25.50 & 83.87 & 84.63 & 84.53 & 86.75 & 84.95 & 1.248 \\
\hline & 27.10 & 82.59 & 82.40 & 84.22 & 83.98 & 83.29 & 0.937 \\
\hline & 30.30 & 64.31 & 69.98 & 70.43 & 65.61 & 67.58 & 3.082 \\
\hline & 34.30 & 47.91 & 47.10 & 48.02 & 47.58 & 47.65 & 0.412 \\
\hline & 37.80 & 34.44 & 33.52 & 40.19 & 37.54 & 36.42 & 3.043 \\
\hline & 43.10 & 21.89 & 18.00 & 24.30 & 26.24 & 22.61 & 3.550 \\
\hline \multirow{7}{*}{$\begin{array}{l}\text { Factor de picazón } \\
\text { (FP) }\end{array}$} & 22.30 & 8.45 & 8.41 & 6.72 & 6.61 & 7.55 & 1.021 \\
\hline & 25.50 & 16.13 & 15.37 & 15.47 & 13.25 & 15.05 & 1.248 \\
\hline & 27.10 & 17.41 & 17.60 & 15.78 & 16.02 & 16.71 & 0.937 \\
\hline & 30.30 & 35.69 & 30.02 & 29.57 & 34.39 & 32.42 & 3.082 \\
\hline & 34.30 & 52.09 & 52.90 & 51.98 & 52.42 & 52.35 & 0.412 \\
\hline & 37.80 & 65.56 & 66.48 & 59.81 & 62.46 & 63.58 & 3.043 \\
\hline & 43.10 & 78.11 & 81.40 & 75.50 & 73.76 & 77.19 & 3.326 \\
\hline
\end{tabular}

refieren a equipos como el OFDA, Laserscan, Airlfow (IWTO-28, 2000; IWTO-12, 2003; IWTO-47, 2007; Cottle y Baxter, 2015) y microscopio de proyección (ASTM, 2001; IWTO-8, 2004).
Cuando el CEF analiza fibras de vicuñas, la exactitud varía entre 0.01 y 0.79 con una media de $0.56 \mu \mathrm{m}$, valores superiores al caso de lana de ovinos y fibras de mohair, cuyos promedios de exactitud son de $0.16 \mathrm{y}$ 
Cuadro 6. Resultados de evaluación de cuatro características en muestras de fibras de vicuñas luego de la calibración, considerando como muestras patrón a la MDF obtenida con el Laserscan, utilizando el Caracterizador Electrónico de Fibras calibrado

\begin{tabular}{|c|c|c|c|c|c|c|c|}
\hline \multirow{2}{*}{ Característica } & \multirow{2}{*}{$\begin{array}{c}\text { MDF- } \\
\text { Laserscan }\end{array}$} & \multicolumn{4}{|c|}{ Mediciones } & \multirow{2}{*}{ Media } & \multirow{2}{*}{ D.E. } \\
\hline & & $1^{\mathrm{a}}$ & $2^{\mathrm{a}}$ & $3^{a}$ & $4^{\mathrm{a}}$ & & \\
\hline $\begin{array}{l}\text { Media de diámetro } \\
\text { de fibra (MDF) }\end{array}$ & $\begin{array}{l}13.5 \\
13.8 \\
13.9 \\
14.3 \\
14.4 \\
14.5\end{array}$ & $\begin{array}{l}13.46 \\
13.41 \\
12.72 \\
13.58 \\
13.93 \\
14.06\end{array}$ & $\begin{array}{l}13.64 \\
13.13 \\
13.25 \\
13.46 \\
13.76 \\
13.71\end{array}$ & $\begin{array}{c}13.45 \\
13.26 \\
13.58 \\
- \\
13.92 \\
13.80\end{array}$ & $\begin{array}{c}13.47 \\
13.31 \\
13.09 \\
- \\
13.67 \\
13.65\end{array}$ & $\begin{array}{l}13.51 \\
13.28 \\
13.16 \\
13.52 \\
13.82 \\
13.81\end{array}$ & $\begin{array}{l}0.091 \\
0.119 \\
0.356 \\
0.091 \\
0.129 \\
0.182\end{array}$ \\
\hline $\begin{array}{l}\text { Desviación } \\
\text { estándar de la } \\
\text { MDF (DEMDF) }\end{array}$ & $\begin{array}{l}13.5 \\
13.8 \\
13.9 \\
14.3 \\
14.4 \\
14.5\end{array}$ & $\begin{array}{l}2.12 \\
2.18 \\
2.45 \\
2.03 \\
2.19 \\
2.31\end{array}$ & $\begin{array}{l}2.04 \\
2.31 \\
2.26 \\
2.14 \\
2.31 \\
2.22\end{array}$ & $\begin{array}{c}2.12 \\
2.27 \\
2.27 \\
-- \\
2.25 \\
2.24\end{array}$ & $\begin{array}{c}2.02 \\
2.20 \\
2.33 \\
-- \\
2.19 \\
2.20\end{array}$ & $\begin{array}{l}2.08 \\
2.24 \\
2.33 \\
2.09 \\
2.24 \\
2.24\end{array}$ & $\begin{array}{l}0.171 \\
0.163 \\
0.059 \\
0.232 \\
0.080 \\
0.138\end{array}$ \\
\hline $\begin{array}{l}\text { Coeficiente de } \\
\text { variación de MDF } \\
(\text { CVMDF })\end{array}$ & $\begin{array}{l}13.5 \\
13.8 \\
13.9 \\
14.3 \\
14.4 \\
14.5\end{array}$ & $\begin{array}{l}14.20 \\
14.57 \\
16.96 \\
13.48 \\
14.33 \\
15.03\end{array}$ & $\begin{array}{l}13.54 \\
15.67 \\
15.28 \\
14.32 \\
15.21 \\
14.69\end{array}$ & $\begin{array}{l}14.19 \\
15.32 \\
15.12 \\
\\
14.70 \\
14.73\end{array}$ & $\begin{array}{l}13.52 \\
14.80 \\
15.82 \\
\\
14.50 \\
14.55\end{array}$ & $\begin{array}{l}13.86 \\
15.09 \\
15.80 \\
13.90 \\
14.69 \\
14.75\end{array}$ & $\begin{array}{l}0.385 \\
0.497 \\
0.831 \\
0.596 \\
0.379 \\
0.203\end{array}$ \\
\hline $\begin{array}{l}\text { Factor de confort } \\
\text { (FC) }\end{array}$ & $\begin{array}{l}13.5 \\
13.8 \\
13.9 \\
14.3 \\
14.4 \\
14.5\end{array}$ & $\begin{array}{l}100 \\
100 \\
100 \\
100 \\
100 \\
100\end{array}$ & $\begin{array}{l}100 \\
100 \\
100 \\
100 \\
100 \\
100\end{array}$ & $\begin{array}{l}100 \\
100 \\
100 \\
100 \\
100 \\
100\end{array}$ & $\begin{array}{l}100 \\
100 \\
100 \\
100 \\
100 \\
100\end{array}$ & $\begin{array}{l}100 \\
100 \\
100 \\
100 \\
100 \\
100\end{array}$ & $\begin{array}{l}0 \\
0 \\
0 \\
0 \\
0 \\
0\end{array}$ \\
\hline
\end{tabular}

Cuadro 7. Desviación estándar, intervalo de confianza al 95\% (IC) y exactitud ${ }^{1}$ de resultados de evaluación de la media de diámetro de fibra (MDF) en muestras de top de fibras de mohair, obtenidas con el Caracterizador Electrónico de Fibras (CEF)

\begin{tabular}{ccccc}
\hline \multirow{2}{*}{ MDF-Patrón } & \multicolumn{5}{c}{ CEF } \\
\cline { 2 - 5 } & Media & D.E. & IC & Exactitud \\
\hline 22.30 & 22.08 & 0.402 & 0.394 & 0.218 \\
25.50 & 25.94 & 0.400 & 0.392 & 0.443 \\
27.10 & 27.02 & 0.160 & 0.157 & 0.077 \\
30.30 & 30.96 & 0.513 & 0.503 & 0.657 \\
34.30 & 34.86 & 0.266 & 0.261 & 0.565 \\
37.80 & 37.58 & 0.483 & 0.474 & 0.215 \\
43.10 & 43.30 & 1.091 & 1.069 & 0.197 \\
\hline
\end{tabular}

${ }^{1}$ Diferencia absoluta de la MDF de la muestra patrón y el promedio obtenido con el CEF 
Cuadro 8. Desviación estándar, intervalo de confianza al 95\% (IC) y exactitud de resultados de evaluación de la media de diámetro de fibra (MDF) en muestras de fibra de vicuñas, obtenidas con el Caracterizador Electrónico de Fibras (CEF), considerando como patrones las evaluaciones reportadas por el Laserscan

\begin{tabular}{ccccc}
\hline \multirow{2}{*}{ MDF-Laserscan } & \multicolumn{4}{c}{ CEF } \\
\cline { 2 - 5 } & Media & D.E. & IC & Exactitud \\
\hline 13.5 & 13.51 & 0.091 & 0.060 & 0.005 \\
13.8 & 13.28 & 0.119 & 0.078 & 0.523 \\
13.9 & 13.16 & 0.356 & 0.232 & 0.740 \\
14.3 & 13.52 & 0.091 & 0.178 & 0.780 \\
14.4 & 13.82 & 0.129 & 0.085 & 0.578 \\
14.5 & 13.81 & 0.182 & 0.119 & 0.693 \\
\hline
\end{tabular}

Cuadro 9. Estadísticos descriptivos de muestras de fibra de cachemira evaluadas con el Caracterizador Electrónico de Fibras (CEF) calibrado

\begin{tabular}{lcccccc}
\hline Características & $\mathrm{n}$ & Media & DE & Mínimo & Máximo & EE \\
\hline Media de diámetro de fibra (MDF) & 16 & 18.94 & 0.99 & 17.47 & 20.63 & 0.25 \\
Desviación estándar de la MDF (DEMDF) & 16 & 4.92 & 0.82 & 4.00 & 6.67 & 0.21 \\
Coeficiente de variación de la MDF (CVMDF) & 16 & 26.02 & 3.33 & 22.49 & 33.35 & 0.83 \\
Factor de confort (FC) & 16 & 96.55 & 2.50 & 91.44 & 98.55 & 0.63 \\
Factor de picazón (FP) & 16 & 3.45 & 2.50 & 1.45 & 8.56 & 0.63 \\
Finura al hilado (FH) & 16 & 19.22 & 1.38 & 17.52 & 21.99 & 0.34 \\
\hline
\end{tabular}

$0.34 \mu \mathrm{m}$; mientras que la desviación estándar varía entre 0.10 y $0.36 \mu \mathrm{m}$ y el intervalo de confianza a $95 \%$ varía entre 0.08 y $0.23 \mu \mathrm{m}$ (Cuadro 8). Estos valores son similares a los obtenidos en lana de ovinos y fibras de mohair, y que indican la precisión del CEF bajo este escenario.

\section{Validación del CEF (fibras de alpacas)}

El coeficiente de correlación entre las mediciones del diámetro de fibra realizadaspor el OFDA2000 modo 100 y el Caracterizador Electrónico de Fibras, bajo condiciones de laboratorio, fue de $0.99 \mathrm{y}$ el coeficiente de regresión fue de 1.2 (Figura 6, izquierda). La correlación bajo condiciones de campo fue similar, pero la regresión fue ligeramente inferior a 1 (Figura 6, derecha). Sin embargo, al evaluar la relación entre ambos equipos con respecto a la desviación estándar (en condiciones de laboratorio), la correlación, aunque disminuye ligeramente $(\mathrm{r}=0.95)$, sigue siendo alta, pero para condiciones de campo, la correlación solo llega a 0.63 (Figura 7). Finalmente, con respecto al factor de confort, la relación entre ambos equipos es alta, tanto para condiciones de laboratorio (0.98) como de campo (0.96) (Figura 8).

Estos datos indican que el CEF tiene también la capacidad de evaluar fibras de alpacas, obteniéndose resultados del diáme- 
(a) MDF OFDA $=-4.532+1.204 * \mathrm{MDF}$ CEF

(b) $r=0.993$

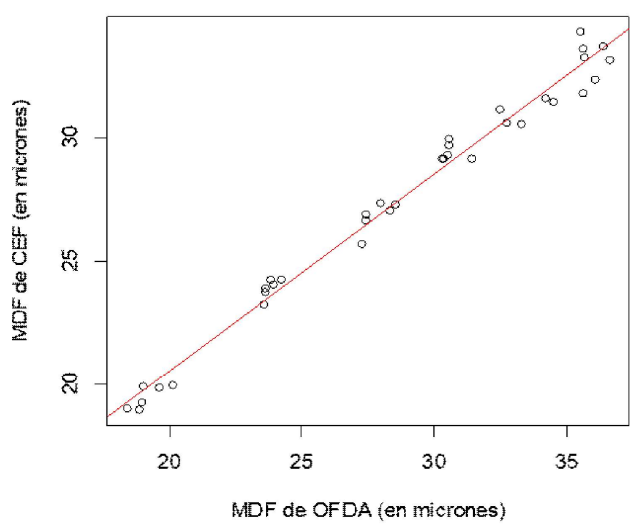

(a) MDF OFDA2000 $=2.916+0.881 *$ MDF CEF (b) $r=0.967$

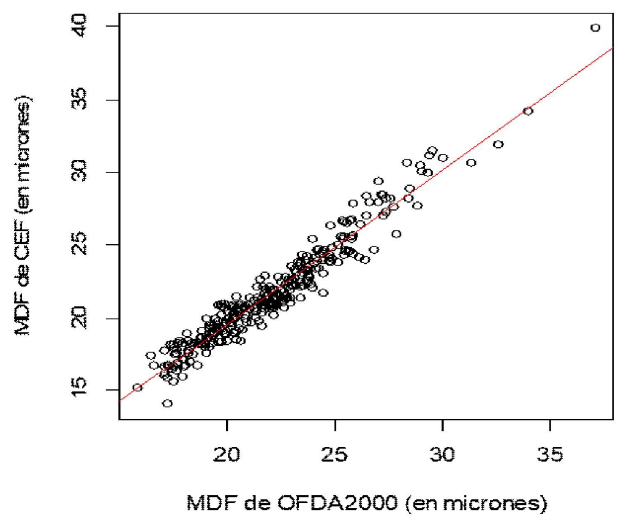

Figura 6. Gráfico de puntos y ajuste lineal de la media de diámetro de fibra (MDF). Izquierda: MDF de fragmentos de tops de fibras de alpacas obtenidas en el OFDA2000 en modo 100 y el Caracterizador Electrónico de Fibras (CEF). Derecha: MDF de mechas de alpacas obtenidas en el OFDA2000 y el CEF. En la parte superior se muestra en (a) la ecuación de regresión y en (b) el coeficiente de correlación de Pearson

(a) DEMDF OFDA $=-5.783+2.270 *$ MDF CEF

(b) $r=0.946$

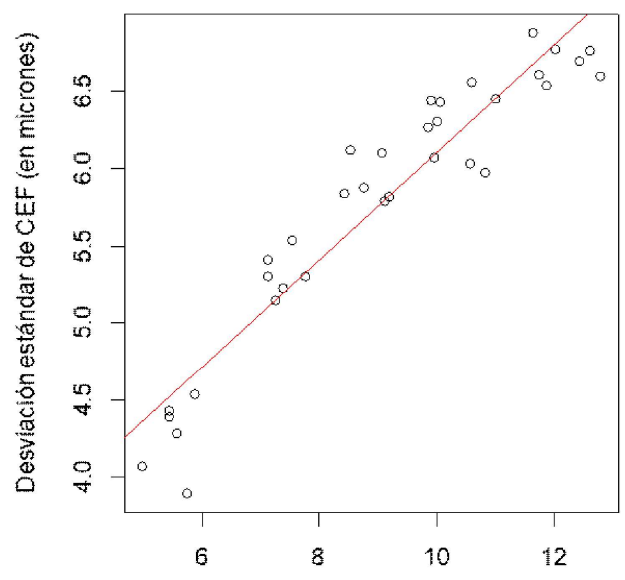

Desviación estándar de OFDA2000 modo 100 (en micrones (a) DEMDF OFDA.2000 $=0.253+0.931 *$ DEMDF CEF

(b) $r=0.634$

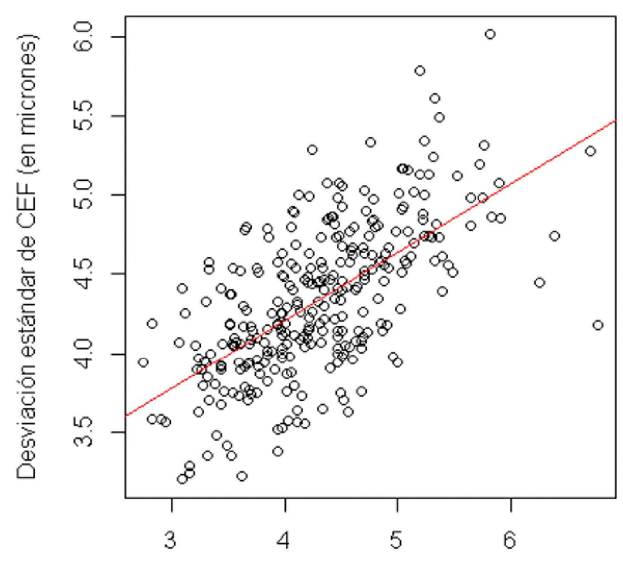

Desviación estándar de OFDA2000 (en micrones)

Figura 7. Gráfico de puntos y ajuste lineal de la desviación estándar de la media de diámetro de fibra (DEMDF). Izquierda: DEMDF de fragmentos de tops de fibras de alpacas obtenidas en el OFDA2000 en modo 100 y el Caracterizador Electrónico de Fibras (CEF). Derecha: DEMDF de mechas de alpacas obtenidas en el OFDA2000 y el CEF. En la parte superior se muestra en (a) la ecuación de regresión y en (b) el coeficiente de correlación de Pearson 


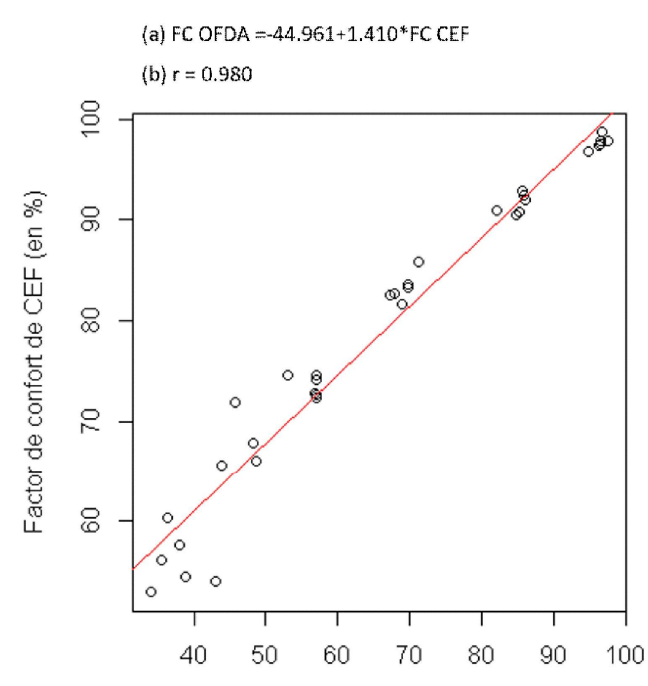

Factor de confort de OFDA.2000 modo 100 (en \%)

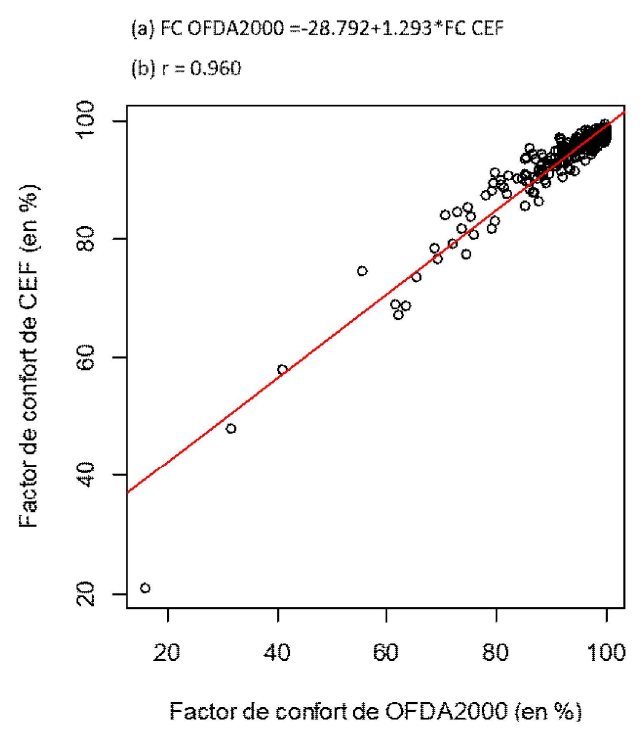

Figura 8. Gráfico de puntos y ajuste lineal del Factor de Confort (FC). Izquierda: del FC de fragmentos de tops de fibras de alpacas obtenidas en el OFDA2000 en modo $100 \mathrm{y}$ el Caracterizador Electrónico de Fibras (CEF). Derecha: del FC de mechas de alpacas obtenidas en el OFDA2000 y el CEF. En la parte superior se muestra en (a) la ecuación de regresión y en (b) el coeficiente de correlación de Pearson

tro de fibra, desviación estándar y factor de confort similar al OFDA2000 en condiciones de laboratorio y de campo, aunque ligeramente diferente para la desviación estándar en condiciones de campo.

\section{Validación del CEF (fibras de cachemira)}

Los promedios el diámetro de fibra, coeficiente de variación y factor de confort de fibras de cachemira utilizando la ecuación utilizada para lana de ovinos se muestran en el Cuadro 9. Los valores se encuentran dentro de los rangos reportados (McGregor, 2004; McGregor y Buttler, 2008; Ansari-Renami et al., 2013). Pese a que no se pudo realizar comparaciones con otros equipos, los resultados comparativos con la bibliografía indican que el CEF también tendría el potencial de evaluar fibras de cachemira.

\section{Conclusiones}

- El caracterizador electrónico de fibras es un equipo compuesto de los componentes óptico, mecánico, electrónico e informático, que interactúan y determinan la media de diámetro de fibra (MDF) y el factor de confort (FC) de ovinos, alpacas y mohair con una precisión que se ajusta a estándares de la IWTO y ASTM, y que dentro de algunos rangos de diámetro de fibra es superior en precisión y exactitud al OFDA 2000 en modo 100.

- El equipo tiene la capacidad de realizar más de 9000 mediciones válidas en 30 segundos por muestra.

- $\quad$ El CEF es capaz de trabajar con fibras de vicuñas y cachemira; sin embargo, es necesario realizar trabajos adicionales para asegurar una buena precisión y exactitud. 


\section{Agradecimientos}

Los autores agradecen al FONDECYT de CONCYTEC que mediante Convenio N. ${ }^{\circ}$ 279-2015-FONDECYT-DE se financió el presente trabajo. Asimismo, al Sr. Rufino Paúcar Chanca por permitir el acceso al Laboratorio de Lanas y Fibras de la UNH.

\section{Literatura Citada}

1. Ansari-Renami H, Rischkowsky B, Mueller J, Moradi S. 2013. Cashmere in Iran. [Internet]. Disponible en: https:/ /www.researchgate.net/publication/ 252932781_Cashmere_In_Iran

2. [ASTM] International Standards and Testing Organization. 2001. Standard test method for diameter of wool and other animal fibers by microprojection. [Internet]. Disponible en: https:// www.astm.org/Standards/D2130.htm

3. Baltuano O, Rojas J, Aching J, Rojas D, Comina G, Díaz J, Rojas A, et al. 2005. Prototipo de fibrómetro digital computarizado para medición automática del espesor de fibra de alpaca. Lima, IPEN [Internet]. Disponible en: http:// alicia.concytec.gob.pe/vufind/Record/ IPEN 22d23894b04a7b7d8719cfb07b44efac

4. Baxter B. 1998. Comparison of Laserscan OFDA and airflow on raw wool samples. In: Nice Meeting of the International Wool Textile Organisation Wellington (IWTO). Report No: RWG 02. France.

5. Baxter P, Marler J. 2004. The 2003 Australian Wool Innovation on-farm fibre measurement instrument evaluation trial - Part 2: Performance in objective classing and ranking for animal selection. In: Commercial Technology Forum of the International Wool Textile Organization (IWTO). Report No: CTF 02. Evian, France.
6. Brims M. 2006. Fibre assessment apparatus and method. Patent No. W0 2007/025350 A1. Australia. [Internet]. Available in: http://google.com/patents/ WO2007025350A1?cl=en\&hl=es

7. Cardellino R, Mueller J. 2008. Wool and other animal fibers in South America. In: Proc Symposium on Natural Fibres. Rome.

8. Cottle D, Baxter B. 2015. Wool metrology research and development to date. Textile Progress 47: 163-315. doi: 10.1080/00405167.2015.1108543

9. Hazelton N. 2009. Instrument Calibration for the $21^{\text {st }}$ Century. In: 57th Annual Meeting of Minnesota Society of Professional Surveyors. St. Cloud, Minnesota, USA.

10. Heath W, Barkhuizen J, Wright O. 2006. The relationship between mean fibre diameter measurements by airflow and laserscan for South African wools. In: Cairo Meeting of the International Wool Textile Organisation Wellington (IWTO). Egypt.

11. [IWTO-8] International Wool Textile Organisation. 2004. Method of determining fibre diameter distribution parameters and percentage of medullated fibres in wool and other animal fibres by the projection microscope. In: IWTO Red Book Specifications. Ed 2015. Brussels: IWTO. $19 \mathrm{p}$.

12. [IWTO-12] International Wool Textile Organisation. 2003. Measurement of the mean and distribution of fibre diameter using the Sirolan-Laserscan fibre diameter analyser. In: IWTO Red Book Specifications. Ed 2015. Brussels: IWTO. $30 \mathrm{p}$.

13. [IWTO-28] International Wool Textile Organisation. 2000. Determination by the airflow method of the mean fibre diameter of core samples of raw wool. In: IWTO Red Book Specifications. Ed 2015. Brussels: IWTO. 37 p. 
14. [IWTO-47] International Wool Textile Organisation. 2007. Measurement of the mean and distribution of fibre diameter of wool using an optical fibre diameter analyser (OFDA). In: IWTO Red Book Specifications. Ed 2015. Brussels: IWTO. 22 p.

15. Li Q, Huang C, Bai L. 2002. Method and system for measuring wool fiber fineness measurement. Patent $\mathrm{N}^{\mathrm{o}}$ CN1359006-A. China. [Internet]. Available in: https://patents.google.com/ patent/CN1359-006A/en?q=-Method$\& \mathrm{q}=$ system $\& \mathrm{q}=$ measuring- $\& \mathrm{q}=$ wool\&oq $=-$ Method + and + system + -for + measuring+wool

16. Marler J, Baxter P. 2004. The 2003 Australian Wool Innovation on-farm fibre measurement instrument evaluation trial. Part 1: Accuracy and Precision Trials. In: Commercial Technology Forum of the International Wool Textile Organization (IWTO). Report No CTF 01. Evian, France.

17. Marler J, Hansford K, McLachlan I. 2002. The Precision of OFDA2000 and FLEECESCAN for estimating the diameter characteristics of fleeces: a case study. Wool Technol Sheep Breed 50: 832-839.

18. McGregor B. 2004. Quality attributes of commercial cashmere. S Afr J Anim Sci 34: 137-140.

19. McGregor B, Butler K. 2008. The effects of cashmere attributes on the efficiency of dehairing and dehaired cashmere length. Text Res J 78: 486-496. doi: $10.1177 / 0040517507087679$
20. Neumaier A, Groeneveld E. 1998. Restricted maximum likelihood estimation of covariances in sparse linear models. Genet Sel Evol 30: 3-26. doi: 10.1186/ 1297-9686-30-1-3

21. Qi K, Lupton C, Pfeiffer F, Minikhiem D, Kumar N, Whittaker A. 1995. Automatic image analysis system for objective measurement of animal fibers. Sheep Goat Res J 11(2): 71-77.

22. Quispe E, Ramos H, Mayhua P, Alfonso L. 2010. Fibre characteristics of vicuña (Vicugna vicugna mensalis). Small Ruminant Res 93: 64-66. doi: 10.1016/j.smallrumres.2010.03.019

23. Quispe MD, Benavidez G, Sauri RA, Bengoechea JJ, Quispe EC. 2017. Development and preliminary validation of an automatic digital analysis system for animal fibre analysis. S Afr J Anim Sci 47: 822-833. doi: 10.4314/ sajas.v47i6.10

24. $R$ Core Team. 2016. R: A language and environment for statistical. [Internet]. Available in: https://www.R-project.org/

25. [UNIDO] United Nations Industrial Development Organization. 2006. Role of measurement and calibration in the manufacture of products for the global market. Vienna: UNIDO. $68 \mathrm{p}$.

26. U.S. Department of Health and Human Services, Food and Drug Administration. 2011. Guidance for industry. Process validation: general principles and practices. Rockville, USA: CDR. 22 p. 